\title{
C-Arm CT - An Adjunct to DSA for Endoleak Classification in Patients with Endovascular Repair of Abdominal Aortic Aneurysms
}

\section{C-Arm-CT - eine wertvolle Ergänzung zur DSA fur Endoleak- Klassifikation bei Patienten nach endovaskulärer Therapie eines Bauchaortenaneurysmas}

Authors

Affiliations
F. K. Wacker ${ }^{1}$, S. Valdeig ${ }^{2}$, H. J. Raatschen ${ }^{1}$, B. C. Meyer ${ }^{1}$

Institute of Diagnostic and Interventional Radiology, University School of Medicine Hannover

Russell H. Morgan Department of Radiology and Radiological Science, Division of Vascular and Interventional Radiology, Johns Hopkins University School of Medicine, Baltimore

Key words
aorta
angiography
interventional procedures
aneurysm

received $\quad 26.2 .2013$ accepted 24.7.2013

Bibliography

DOI http://dx.doi.org/ 10.1055/s-0033-1350500

Published online: 2.9.2013

Fortschr Röntgenstr 2014; 186:

247-252 @ Georg Thieme

Verlag KG Stuttgart · New York . ISSN 1438-9029

\section{Correspondence}

Herr Priv.-Doz. Dr.

\section{Bernhard C Meyer}

Institut für Radiologie,

Medizinische Hochschule

Hannover

Carl-Neuberg-Str. 1

30625 Hannover

Germany

Tel.: ++49/51/15323421

Fax: ++49/51/15329421

meyer.bernhard@

mh-hannover.de

\section{Zusammenfassung}

$\nabla$

Ziel: Bestimmung der Wertigkeit der C-Arm-CT zur Klassifikation und Steuerung der interventionellen Therapie von Endoleckagen (EL) nach endovaskulärer Stentgrafttherapie (EVAR) abdomineller Aortenaneurysmen (AAA).

Material und Methode: 12 Patienten mit in der CT diagnostiziertem EL und unklarer EL Klassifizierung (ELC) wurden mittels DSA und transarteriell kontrastmittelverstärkter C-Arm-CT untersucht. Die ELC (basierend auf DSA, C-Arm-CT und CT) im Rahmen der angiografischen Untersuchung diente als Referenzstandard (SOR); Die anschließend durch einen verblindeten zweiten Leser entweder anhand der DSA oder der C-Arm-CT-Bilder erhobene ELC wurde mit dem SOR verglichen. Im Fall einer interventionellen Therapie $(n=6)$ wurde der Mehrwert der C-Arm-CT zur Planung der Intervention retrospektiv erhoben (1: essenziell, 2: hilfreich, 3: Zusatzinformation ohne Relevanz, 4: keine Zusatzinformation).

Ergebnisse: Durch den verblindeten Radiologen wurden basierend auf der DSA 9/12 EL und basierend auf der C-Arm-CT 11/12 EL korrekt klassifiziert. Bei einem Patienten war die zeitliche Auflösung der DSA für die korrekte ELC zielführend. Bei 6 Patienten wurde ein Typ-2-EL ohne Behandlungsbedarf diagnostiziert. Bei den verbleibenden 6 Patienten wurde das EL sofort behandelt (Typ1-EL, $n=4: 3$ Stentgraftverlängerungen und eine Angioplastie; Typ-2-EL, $\mathrm{n}=1$ : perkutane Embolisation; Typ-3-EL, $\mathrm{n}=1$ : Überdeckung des Materialfehlers). Der Mehrwert der C-Arm-CT wurde bei 3 Patienten als essenziell und bei 2 als hilfreich bewertet.

Schlussfolgerungen: Die C-Arm-CT ist eine gute Ergänzung zur DSA. Lokalisierung und Klassifikation von Endoleaks gelang in unserer Pilotstudie zuverlässiger als mit alleiniger DSA.

\section{Abstract \\ $\nabla$}

Purpose: To assess the benefit of C-arm CT for classification and procedural guidance during interventional therapy of endoleaks (EL) after endovascular repair (EVAR) of abdominal aortic aneurysms (AAA).

Materials and Methods: 12 patients with EL diagnosed with CT but undetermined EL classification (ELC) underwent DSA and transarterial contrastenhanced C-arm CT. ELC (based on DSA, C-arm $\mathrm{CT}$ and $\mathrm{CT}$ ) assessed during the angiographic procedure served as the standard of reference (SOR). Subsequently, ELC was assessed by a blinded second reader based on DSA or C-arm CT and compared to the SOR. In the case of an interventional procedure $(n=6)$, the added value of $C$-arm CT for procedure guidance was assessed retrospectively (1: essential, 2: helpful, 3: additional information without impact, 4 : no additional information). Results: The blinded reader classified 9/12 EL using DSA alone and 11/12 EL using C-arm CT alone. In one patient, the temporal resolution provided by DSA was essential to establish the diagnosis. In 6 patients, a type $2 \mathrm{EL}$ without need for therapy was diagnosed. The remaining 6 patients showed EL that were treated immediately (type $1 \mathrm{EL}, \mathrm{n}=4: 3$ stent graft extensions and one angioplasty; type 2 $\mathrm{EL}, \mathrm{n}=1$ : translumbar embolization; type $3 \mathrm{EL}$, $\mathrm{n}=1$ : sealing of a fabric tear). The information provided by C-arm CT was assessed to be essential in three patients and helpful in two.

Conclusion: C-arm CT is an ideal adjunct to DSA. In our pilot study, it helped to localize and classify endoleaks more reliably than DSA alone.

Citation Format:

- Wacker FK, Valdeig S, Raatschen HJ et al. C-Arm CT - An Adjunct to DSA for Endoleak Classification in Patients with Endovascular Repair of Abdominal Aortic Aneurysms. Fortschr Röntgenstr 2014; 186: 247-252 


\section{Introduction}

$\nabla$

Endovascular repair (EVAR) of abdominal aortic aneurysms (AAA) was introduced by Parodi and coworkers in 1991 [1]. In the last two decades, EVAR has emerged as an important alternative to open surgery for selected patients [2, 3]. Unlike patients who are treated with open AAA repair, patients undergoing EVAR require lifelong image surveillance with cross-sectional imaging to monitor the position of the device, to ensure stent graft function, and to detect complications. The occurrence of endoleaks (EL) after EVAR remains one of its principal and most frequent complications [4].

In most centers, bi- or triphasic MDCT is used for follow-up after EVAR with high sensitivity for the presence of endoleaks [5]. Once an EL is detected, high-quality imaging for exact classification is warranted to guide therapy [6]. Although CE ultrasound [7], time-resolved CT [8] and MRI [9] have shown promising results in the classification of EL that are difficult to assess with standard follow-up, DSA is still considered the gold standard due to its high temporal and spatial resolution and its ability to depict flow direction [5]. Another benefit is the ability to perform interventional treatment in the same setting if necessary.

Disadvantages include arterial puncture and the lack of cross-sectional soft tissue information since DSA provides only projection images. This often leads to multiple views and contrast injections to clearly depict feeding arteries of an endoleak free from superimposing structures such as the aorta, the stent graft or other arteries. In contrast to its extremely high spatial resolution, DSA provides limited low-contrast resolution. Therefore, strong contrast enhancement of the endoleak has to be obtained to make it visible. It is well known that small, slow-flow endoleaks can be missed by DSA alone [8, 9].

Cone-beam C-arm CT facilitates acquisition and reconstruction of CT-like images in a flat-panel angiography system. The ability to combine real-time fluoroscopy and DSA with C-arm CT has helped to overcome shortcomings during many interventional procedures [10-12]. For EVAR, there are case reports that demonstrated the feasibility of the intraoperative use of C-arm CT during the EVAR procedure [13-15]. Binkert et al. and van Bindsbergen et al. used C-arm CT to guide translumbar endoleak repair by direct puncture of the perfused aneurysm sac in three and five patients, respectively $[16,17]$. However, to the best of our knowledge, the use of C-arm CT for endoleak classification has not been described.

The aim of this study was to investigate the value of C-arm CT as an adjunct to DSA for the classification of endoleaks that could not be classified with noninvasive diagnostic tests.

\section{Method \\ $\nabla$}

\section{Patient population}

Over a time period of two years, 12 patients with an endoleak detected on a triphasic (unenhanced, arterial and late phase) MDCT follow-up exam 3 to 9 months after EVAR that could not be classified [18] with MDCT were included in this retrospective study. All 12 patients were referred to interventional radiology and underwent digital subtraction angiography (DSA) and angiographic C-arm CT using a flat-panel C-Arm CT (C-arm CT, Axiom Artis dBA, Siemens, Forchheim, Germany) according to a standard image acquisition protocol. Each patient gave informed written consent to perform the angiographic study. The retrospective evalu- ation was approved by the institutional review board with a waiver of consent granted.

\section{Imaging technique}

DSA was performed using an angiographic system (Axiom Artis ${ }^{\circledR}$, Siemens Medical, Forchheim, Germany) equipped with a $30 \times 40 \mathrm{~cm}$ flat-panel detector. First, digital subtraction angiography of the aorta (5F Pigtail catheter, $30 \mathrm{~mL}$ of iomeprol (Iomeron, Bracco); $300 \mathrm{mg} \mathrm{I} / \mathrm{mL}$; flow rate, $20 \mathrm{~mL} / \mathrm{s}$, catheter tip $1 \mathrm{~cm}$ above the proximal stent graft margin) was performed. Second, the catheter was left in place and a contrast-enhanced C-arm CT scan of the abdominal aorta and the pelvic arteries was acquired (rotation time $8 \mathrm{~s}$, total scan angle $240^{\circ}$, projection angle increment $0.5^{\circ}$, dose per pulse $0.36 \mu \mathrm{Gy}$ ) in the arterial phase (contrast injection: $30 \mathrm{~mL}$ of iomeprol diluted with $30 \mathrm{~mL}$ of saline for a iodine concentration of $150 \mathrm{mg} \mathrm{I} / \mathrm{mL}$; flow rate, $8 \mathrm{~mL} / \mathrm{s}$; no delay). The cylindrical scan had a cranio-caudal coverage of $185 \mathrm{~mm}$ and a transverse and sagittal scan range of $225 \mathrm{~mm}$. For image reconstruction, the raw dataset was sent to a dedicated $3 \mathrm{D}$ image reconstruction workstation (X-Leonardo ${ }^{\circledR}$, Siemens Healthcare, Erlangen, Germany) to generate an isotropic voxel dataset with a typical voxel size of $0.4 \mathrm{~mm}$. The dataset was visualized using multiplanar reconstructions, maximum intensity projections as well as volume rendering techniques. The generation of a $3 \mathrm{D}$ dataset with a $512 \times 512$ matrix took less than 1 minute as a $100 \mathrm{mBit} / \mathrm{s}$ network connection between the C-arm system and the reconstruction workstation was used.

\section{Data evaluation}

During the procedure, DSA, fluoroscopy, and C-arm CT images were reviewed on a workstation by one reader who had access to all available patient information and prior imaging (pre- and post-EVAR MDCT). The type of endoleak was assessed based on all available information first to make a treatment decision and to assess the optimal therapeutic approach during the procedure and second to serve as the standard of reference (SOR) for this study. Subsequently, a blinded second reader (not involved in the procedure) retrospectively evaluated DSA and C-arm CT separately in random order to assess the endoleak classification based on each of the two imaging methods alone.

In case of an interventional treatment $(n=6)$, the second reader subsequently assessed the value of the C-arm CT images for procedure planning on a 4-point scale (1: essential information for procedure guidance, could not have done without it; 2 : helpful information, did alter the course of the intervention, 3: additional information, did not alter the course of the intervention; 4: no additional information).

\section{Results \\ $\nabla$}

The EL could be visualized and classified successfully by use of the intraprocedural imaging including $\mathrm{C}$-arm $\mathrm{CT}$ and all prior imaging by reader 1 in all cases. In 4 patients, a type $1 \mathrm{EL}$ (proximal neck, type 1a: 1 patient; distal neck, type $1 \mathrm{~b}: 3$ patients, $\bullet$ Fig. 1 ) was diagnosed. In 7 patients, the EL could be determined as a type $2 \mathrm{EL}$ with retrograde filling of the aneurysm sac from either the inferior mesenteric artery $(n=2)$ or the lumbar arteries $(n=5)(\bullet$ Fig. 2$)$. In one patient, DSA at an early phase revealed a defect in the graft material ( $\bullet$ Fig. 3 ) resulting in a type 3 EL.

The absolute numbers of patients with agreement or disagreement of endoleak classification of DSA alone or C-Arm CT alone 

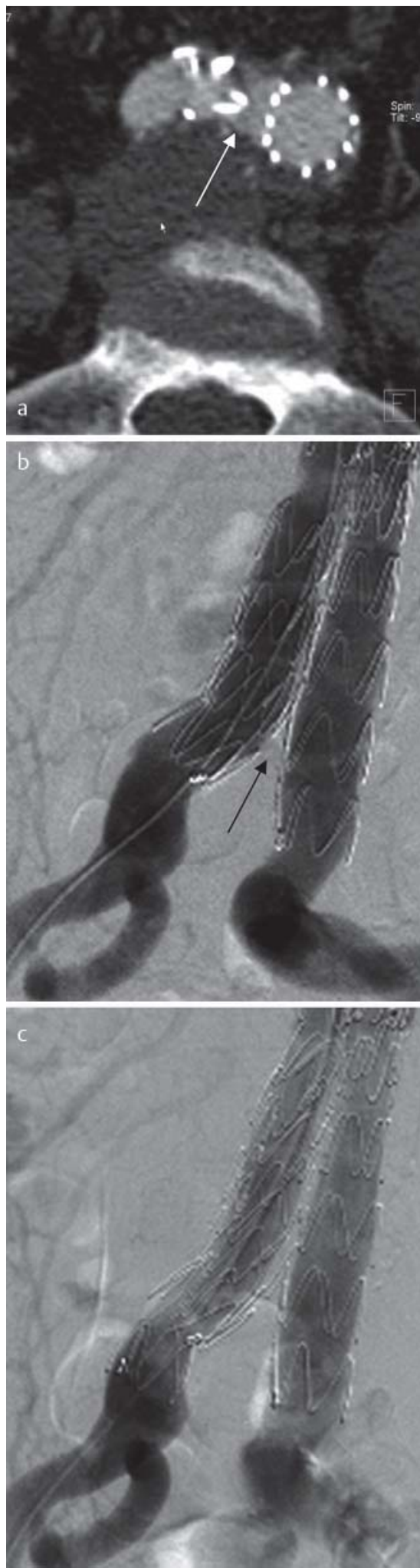

Fig. 1 Patient with a type $1 \mathrm{~B}$ endoleak at the distal attachment site of the right iliac limb of the graft. C-arm CT a shows the endoleak in between the two limbs (arrow in a) without contrast-enhanced lumbar arteries as an indirect sign for incomplete attachment of the endoprosthesis limb. $\mathbf{b}$ DSA shows a faint contrast extravasation between the endoprosthesis limbs (arrow in b), which was missed by the blinded reader. c DSA obtained after placement of a covered stent over iliac attachment site shows no further leak.

Abb. 1 Patient mit einem Typ-1B-Endoleak am distalen Ende des rechtsseitigen Prothesenschenkels. Die CArm-CT a stellt neben dem Endoleak auch das unvollständige Anliegen der Endoprothese dar (Pfeil in a). Die DSA b zeigt einen schwach abgrenzbaren Kontrastmittelaustritt (Pfeil in b) dar, der durch den zweiten Radiologen übersehen wurde. Die DSA c nach Implantation eines gecoverten Stents zeigt kein Endoleak mehr.

compared to SOR are shown in $\bullet$ Table 1. With DSA alone, 9 ELs could be correctly classified. In 3 patients, 1 type 1 and 2 type 2 ELs were missed. This was probably due to slow filling of the EL, DSA artifacts and superimposition of the stent graft.

Using the monophasic cross-sectional C-arm CT data, 11 ELs could be correctly classified. In one patient, C-arm CT misleadingly demonstrated a type 2 endoleak with contrast in the sac in close proximity to a lumbar artery ( $\bullet$ Fig. 3 ). However, DSA at an

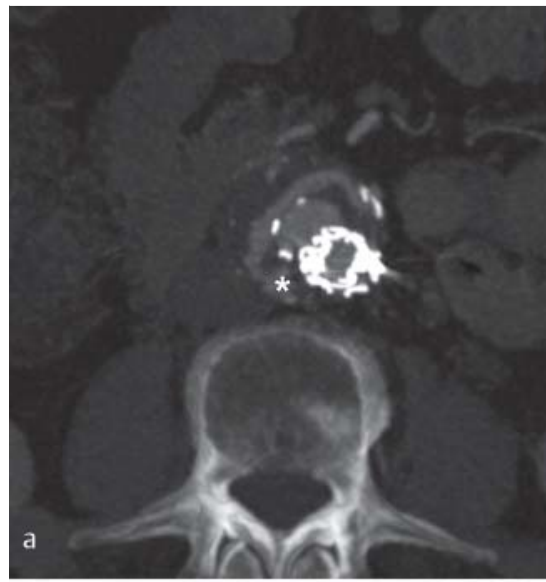

Fig. 2 Patient with type 2 endoleak (asterisk in $\mathbf{a}-\mathbf{c}$ ) detected with MDCT (a transverse MIP, arterial phase). C-Arm CT (b, c transverse and coronal MIP) clearly depicts the feeding lumbar arteries (white arrows in $\mathbf{b}, \mathbf{c}$ ) at the same slice position. Coronal MIP c of C-arm CT visualizes lumbar arteries as well as a third feeding artery arising from the left internal

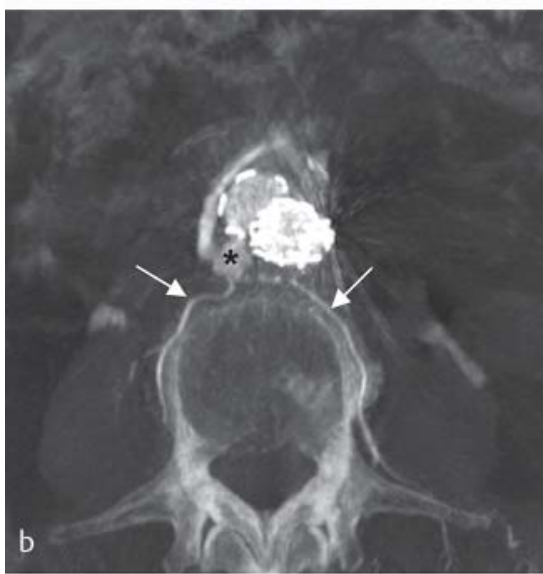

iliac artery (black arrow in c).

Abb. 2 Patient mit in der MDCT (a transversale MIP in der arteriellen Phase) detektiertem Typ-2-Endoleak (Stern in a-c). In der C-Arm$\mathrm{CT}$ (b, $\mathbf{c}$ transversale und koronare MIP) in gleicher Position stellen sich das Endoleak füllende Lumbalarterien (weiße Pfeile in b, c) dar. Die coronare MIP der C-Arm CT zeigt ne-

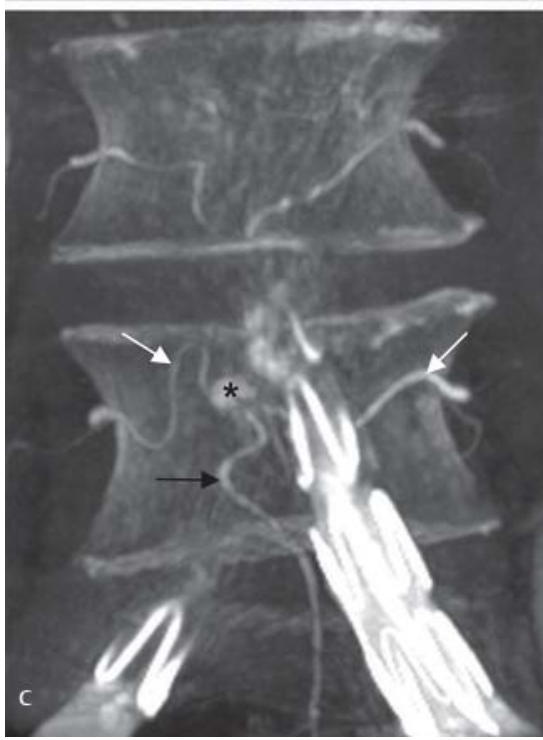
ben den Lumbalarterien zusätzlich eine dritte speisende Arterie, die aus der linken $A$. iliaca interna hervorgeht (schwarzer Pfeil in c).

early phase revealed a defect in the graft material ( $\bullet$ Fig. 3c) resulting in a type 3 endoleak classification.

All patients with type 1 EL were treated. In 3 patients, the stent graft was extended proximally $(n=1)$ or distally ( $n=2$, 0 Fig. 1 ). In one patient, an angioplasty of the distal neck was successfully performed. In 6 of 7 patients with type $2 \mathrm{EL}$, the diameter of the aneurysm sac was stable when compared to the post-EVAR MDCT. In these patients, no immediate therapy was performed. In one case, an increasing AAA sac diameter was noted and a translumbar embolization of the aneurysm sac was performed using C-arm CT-based needle tracking. In the patient with a type 3 endoleak, the fabric tear in the iliac limb was successfully 


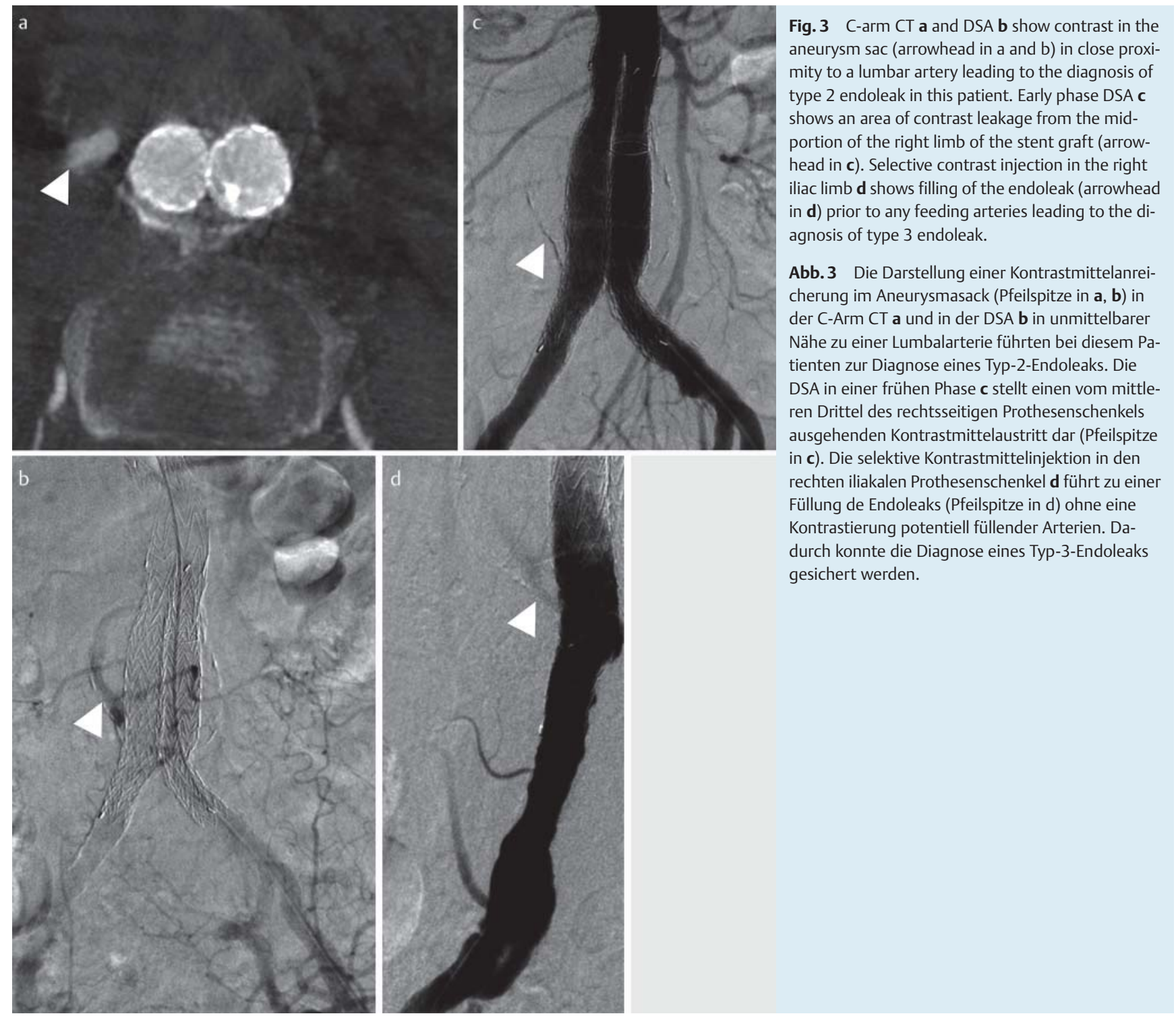

Table 1 Endoleak classification in DSA and C-arm CT.

Tab. 1 Endoleak-Klassifikation in der DSA und im C-Arm CT.

\begin{tabular}{|c|c|c|c|}
\hline \multirow[b]{2}{*}{ patients (n) } & \multicolumn{3}{|c|}{ endoleak classification } \\
\hline & SOR & DSA only & C-arm CT only \\
\hline$\Sigma=8$ & \multicolumn{3}{|c|}{ agreement } \\
\hline 1 & type 1a & $=$ & $=$ \\
\hline 2 & type $1 \mathrm{~b}$ & $=$ & $=$ \\
\hline 5 & type 2 & $=$ & $=$ \\
\hline$\Sigma=3$ & \multicolumn{3}{|c|}{ disagreement of SOR and DSA } \\
\hline 1 & type 1b & $\mathrm{ND}^{*}$ & $=$ \\
\hline 2 & type 2 & ND* & $=$ \\
\hline$\Sigma=1$ & \multicolumn{3}{|c|}{ disagreement of SOR and C-arm CT } \\
\hline 1 & type 3 & $=$ & type $2^{*}$ \\
\hline
\end{tabular}

SOR: Standard of reference, *: Endoleak classification disagreed with the SOR, =: Endoleak classification agreed with the SOR, ND: Not diagnosed/no classification assessed. SOR: Referenzstandard, ${ }^{*}$ : Endoleak-Klassifikation stimmt nicht mit dem Referenzstandard überein, $=$ : Endoleak-Klassifikation stimmt mit dem Referenzstandard überein, ND: keine Diagnose möglich/keine Klassifikation möglich.

covered using a stent graft extension. Subsequently, filling of the endoleak was eliminated which proved the diagnosis of a type 3 endoleak.

In all 6 patients who underwent interventional therapy, the information provided by $\mathrm{C}$-arm CT to plan the respective procedure was assessed by the second reader to be essential in 3 patients and helpful in 2, mainly due to exact localization of the EL. In one patient, C-arm CT provided additional information with respect to stent position and anatomy but had no influence on the course of the intervention.

\section{Discussion}

Digital flat detectors allow CT-like soft tissue images in the angiography suite, adding a third dimension to the normally planar DSA images. Although somewhat limited in field of view and image quality when compared to MDCT, the seamless integration of C-arm CT in the interventional suite offers a tremendous improvement in the workflow during complex procedures [19]. There are a few case reports on the use of C-arm CT in the realm of EVAR procedures that demonstrated the feasibility during im- 
plantation [13-15, 20]. Two case studies reported the use of Carm CT guidance for endoleak repair [16, 17]. In one study [17], contrast-enhanced C-arm CT was used to visualize the endoleak nidus. However, to the best of our knowledge, the use of C-arm CT to classify endoleaks that are difficult to assess by MDCT has not been described.

With any imaging method, the presence of contrast material in the excluded aneurysm sac after EVAR leads to the diagnosis of an endoleak. Once detected, endoleak classification is critical for patient care. Studies using CTA and MRA alone or in combination yield a high number of undetermined ELs ranging from 40 to 60 percent with relatively poor interobserver agreement [9, 21, 22]. All imaging modalities have specific shortcomings that can make reliable classification difficult. With both, CTA and MRA, scan timing can be challenging. This has led to studies using dynamic CTA with promising results [8] but a relatively high radiation dose. MRA has shown some potential for EL classification but is limited to grafts that do not create a susceptibility artifact $[9,23$, 24]. CEUS is a dynamic study that overcomes timing issues with CTA and MRA but has difficulties visualizing both endoleak nidus and feeding vessels, especially in obese patients $[5,7,23]$. Therefore, in some cases exact classification requires the use of DSA which is, despite some shortcomings of its own, still considered the gold standard for endoleak classification, and should be performed especially in cases with a growing sac and equivocal CTA $[5,25]$. DSA provides high spatial and temporal resolution and is able to depict flow direction [26]. However, it is recognized to have limited sensitivity for identifying small ELs with slow flow [5]. Here, additional 3 D C-arm CT information in combination with intra-arterial contrast injection adds valuable information. In our study, we successfully acquired C-arm CT images on the angiography table with an intra-arterial angiographic catheter facilitating high intra-arterial contrast medium density in comparison to conventional MDCT. We were able to determine the presence of contrast agent in the sac in all patients and could correctly classify the endoleak in all but one case based on C-arm CT only. Moreover, the full integration of angiography and C-Arm CT provided information that helped to guide immediate therapy with the patient never leaving the angio suite.

The main limitations of our study were the small number of patients referred to DSA with undetermined endoleaks and the retrospective evaluation. Although a prospective study with a larger series would be beneficial to assess the technique, we believe that, due to our standardized approach for both DSA and C-arm $\mathrm{CT}$, the results are still meaningful. Another limitation is that the reference standard is based on reading of one operator during the intervention. However, this reading was performed using all available information including DSA and fluoroscopy with the latter not being saved. Therefore, a second reading was not possible. However, in contrast to many studies on endoleak follow-up that did not have a reference standard, we had a true gold standard for 6 patients who were treated in the same setting with a negative finding for the presence of contrast media on follow-up after treatment.

\section{Conclusion}

Endovascular repair of aortic aneurysms is performed with increasing frequency. Imaging surveillance is mandatory in EVAR patients to detect complications. Even with reduced follow-up protocols, there will always be endoleaks that require exact clas- sification, especially if expansion of the aneurysm sac is observed $[5,27]$. For such cases, C-arm CT offers an ideal adjunct to DSA as it helps to localize and classify endoleaks.

\section{Acknowledgement}

$\nabla$

This manuscript is dedicated to Professor Bernd Hamm for his 60th birthday.

\section{References}

1 Parodi JC, Palmaz JC, Barone HD. Transfemoral intraluminal graft implantation for abdominal aortic aneurysms. Annals of vascular surgery 1991; 5: $491-499$

2 Eberhardt KM, Treitl M, Sadeghi-Azandaryani M. An endovascular technique for treatment of high-risk iatrogenic aortic pseudoaneurysms with the ethylene vinyl alcohol copolymer onyx and aortic stent grafting. Fortschr Röntgenstr 2012; 184: 1163 -1165

3 Goltz JP, Basturk P, Hoppe H et al. Emergency and elective implantation of covered stent systems in iatrogenic arterial injuries. Fortschr Röntgenstr 2011; 183: 618-630

4 Rutherford RB. Open Versus Endovascular Stent Graft Repair for Abdominal Aortic Aneurysms: An Historical View. Seminars in Vascular Surgery 2012; 25: $39-48$

5 Stavropoulos SW, Charagundla SR. Imaging techniques for detection and management of endoleaks after endovascular aortic aneurysm repair. Radiology 2007; 243: 641-655

6 van den Berg JC. Commentary: Type II endoleaks: still the crux of EVAR? Journal of endovascular therapy: an official journal of the International Society of Endovascular Specialists; 2012; 19: 209-212

7 Clevert DA, Horng A, Kopp R et al. Kontrastmittelverstärkter Ultraschall im Follow-up nach endovaskulärer Stentversorgung eines infrarenalen Bauchaortenaneurysmas. Radiologe 2009; 49: 1033-1039

8 Sommer WH, Becker CR, Haack M et al. Time-resolved CT Angiography for the Detection and Classification of Endoleaks. Radiology 2012; 263: 917 - 926

9 Alerci M, Oberson M, Fogliata A et al. Prospective, intraindividual comparison of MRI versus MDCT for endoleak detection after endovascular repair of abdominal aortic aneurysms. European radiology 2009; 19: $1223-1231$

10 Iwazawa J, Ohue S, Hashimoto $N$ et al. Detection of Hepatocellular Carcinoma: Comparison of Angiographic C-Arm CT and MDCT. American Journal of Roentgenology 2010; 195: 882 - 887

11 Huppert PE, Firlbeck G, Meissner OA et al. C-arm CT for chemo-embolization of liver tumors. Radiologe 2009; 49: 830-836

12 Meyer BC, Frericks BB, Voges $M$ et al. Visualization of Hypervascular Liver Lesions During TACE: Comparison of Angiographic C-Arm CT and MDCT. American Journal of Roentgenology 2008; 190: W263W269

13 Biasi L, Ali T, Hinchliffe R et al. Intraoperative DynaCT detection and immediate correction of a type Ia endoleak following endovascular repair of abdominal aortic aneurysm. Cardiovascular and interventional radiology 2009; 32: 535-538

14 Eide KR, Ødegård A, Myhre HO et al. Initial Observations of Endovascular Aneurysm Repair Using Dyna-CT. Journal of Endovascular Therapy 2007; $14: 50-53$

15 Rabitsch E, Celedin S, Kau T et al. Flat-panel CT as a new perinterventional imaging modality in aortic stentgraft procedures-work in progress. Fortschr Röntgenstr 2008; 180: 127-133

16 Binkert CA, Alencar H, Singh J et al. Translumbar type II endoleak repair using angiographic CT. Journal of vascular and interventional radiology: JVIR 2006; 17: 1349-1353

17 van Bindsbergen L, Braak SJ, van Strijen MJL et al. Type II Endoleak Embolization after Endovascular Abdominal Aortic Aneurysm Repair with Use of Real-time Three-dimensional Fluoroscopic Needle Guidance. Journal of Vascular and Interventional Radiology 2010; 21: 1443 1447

18 White GH, Yu W, May J et al. Endoleak as a Complication of Endoluminal Grafting of Abdominal Aortic Aneurysms: Classification, Incidence, Diagnosis, and Management. Journal of Endovascular Surgery 1997; 4: $152-168$ 
19 Hausegger KA, Furstner M, Hauser $M$ et al. Clinical application of flatpanel CT in the angio suite. Fortschr Röntgenstr 2011; 183: 11161122

20 Dijkstra ML, Eagleton MJ, Greenberg RK et al. Intraoperative C-arm cone-beam computed tomography in fenestrated/branched aortic endografting. Journal of vascular surgery 2011; 53: 583-590

21 Chernyak V, Rozenblit AM, Patlas $M$ et al. Type II endoleak after endoaortic graft implantation: diagnosis with helical CT arteriography. Radiology 2006; 240: 885-893

22 van der Laan MJ, Bartels LW, Viergever MA et al. Computed tomography versus magnetic resonance imaging of endoleaks after EVAR. European journal of vascular and endovascular surgery: the official journal of the European Society for Vascular Surgery 2006; 32: 361 - 365

23 Cantisani V, Ricci P, Grazhdani H et al. Prospective Comparative Analysis of Colour-Doppler Ultrasound, Contrast-enhanced Ultrasound, Computed Tomography and Magnetic Resonance in Detecting Endo- leak after Endovascular Abdominal Aortic Aneurysm Repair. European Journal of Vascular and Endovascular Surgery 2011; 41: 186-192

24 Pitton MB, Schweitzer H, Herber S et al. MRI Versus Helical CT for Endoleak Detection After Endovascular Aneurysm Repair. American Journal of Roentgenology 2005; 185: 1275 - 1281

25 Shah A, Stavropoulos SW. Imaging Surveillance following Endovascular Aneurysm Repair. Seminars in interventional radiology 2009; 26: $10-16$

26 Stavropoulos SW, Clark TW, Carpenter JP et al. Use of CT angiography to classify endoleaks after endovascular repair of abdominal aortic aneurysms. Journal of vascular and interventional radiology: JVIR 2005; 16: $663-667$

27 Karthikesalingam A, Thrumurthy SG, Jackson D et al. Current evidence is insufficient to define an optimal threshold for intervention in isolated type II endoleak after endovascular aneurysm repair. Journal of endovascular therapy: an official journal of the International Society of Endovascular Specialists 2012; 19: $200-208$ 